\title{
ВИКОРИСТАННЯ МЕТОДУ МОНТЕ-КАРЛО ДЛЯ МАРКОВСЬКИХ ЛАНЦЮГІВ ДЛЯ ПРОГНОЗУВАННЯ ПОШИРЕНОСТІ ІШЕМІЧНОЇ ХВОРОБИ СЕРЦЯ В УКРAїHI
}

\author{
М. А. Іванчук, П. Р. Іванчук \\ Вищий державний навчальний заклад України \\ «Буковинський державний медичний університет»
}

В роботі запропоновано використання марковських ланцюгів для опису поширеності ішемічної хвороби серця в Україні. Використано метод Монте-Карло для прогнозування поширеності IXC в найближчі 10 років. Прогнозується зростання поширеності IXC в Україні до 35 041,2 на 100 тис. населення у 2025 році.

Ключові слова: ішемічна хвороба серця, прогнозування, епідеміологія, ланцюг Маркова, методи Монте-Карло.

\section{USING THE MONTE CARLO MARKOV CHAIN TO PREDICT THE PREVALENCE OF CORONARY HEART DISEASE IN UKRAINE}

\author{
M. A. Ivanchuk, P. R. Ivanchuk \\ Higher State Educational Establishment of Ukraine \\ "Bucovinian State Medical University"
}

\begin{abstract}
In medical forecasting, there are often challenges in which it is necessary to assess the risk that is continuous for a long time, and important events can occur more than once. One of the ways of solving problems of this type is the use of Markov models.

Markov models suggest that the patient is always in one of the finite numbers of discrete states of health, called the Markov states. All events are modeled as a transition from one state to another. In order for the Markov chain to end, it must contain at least one absorbing state from which the patient can't pass into other states. In medical models, such a condition is the death of the patient, as this is the only condition from which the patient can't escape. The purpose of this work is to build a Markov chain for predicting the prevalence of coronary heart disease in Ukraine

To test the predictive quality, the model was built since 1996. The data obtained for the model for 1996-2012 were compared with known epidemiological data. The average prediction error is $3.2 \%$. We predict an increase in the incidence of coronary heart disease to 35041.2 per 100000 population in 2025.
\end{abstract}

Key words: coronary heart disease, prediction, epidemiology, Markov chain, Monte Carlo methods.

\section{ИСПОЛЬЗОВАНИЕ МЕТОДА МОНТЕ-КАРЛО ДЛЯ МАРКОВСКОЙ ЦЕПИ ДЛЯ ПРОГНОЗИРОВАНИЯ РАСПРОСТРАНЕННОСТИ ИШЕМИЧЕСКОЙ БОЛЕЗНИ СЕРДЦА В УКРАИНЕ}

\author{
М. А. Иванчук, П. Г. Иванчук \\ Высшее государственное учебное заведение Украины \\ «Буковинский государственный медицинский университет» \\ В работе предложено использование марковских цепей для описания распространенности ишемической болезни \\ сердца в Украине. Использован метод Монте-Карло для прогнозирования распространенности ИБС в ближайшие \\ 10 лет. Прогнозируется рост распространенности ИБС в Украине в 35 041,2 на 100 тыс. населения в 2025 году.
}

Ключевые слова: ишемическая болезнь сердца, прогнозирование, эпидемиология, цепь Маркова, методы Монте-Карло. 
Вступ. У медичному прогнозуванні нерідко зустрічаються завдання, в яких необхідно оцінити ризик, що $є$ неперервним впродовж тривалого часу, а важливі події можуть відбутися більше ніж один раз. Одним із шляхів розв'язку завдань цього типу $\epsilon$ використання дерев, проте у задачах медичного використання цей шлях є складним і може потребувати значних спрощень. J. R. Beck iз співавторами у роботах $[6,7]$ описали використання марковських моделей для прогнозування у медицині.

Марковські моделі припускають, що пацієнт завжди знаходиться в одному із скінченої кількості дискретних станів здоров'я, що називаються марковськими станами. Всі події моделюються як перехід з одного стану в інший. Часовий простір аналізу розділяється на рівні часові проміжки (цикли), впродовж яких пацієнт із певною ймовірністю може перейти з одного стану в інший. Довжина циклу вибирається так, щоб представляти клінічно значимий проміжок часу. Так, наприклад, для моделі, що охоплює все життя пацієнта, цикл може становити один рік. У залежності від швидкості зміну станів пацієнта, довжина циклу для різних моделей може коливатися в дуже широких межах.

Для того, щоб ланцюг Маркова завершився, він повинен містити хоча б один поглинаючий стан, 3 якого пацієнт не може перейти в інші стани. В медичних моделях таким станом є смерть пацієнта, оскільки це єдиний стан, з якого пацієнт не може вийти. Зазвичай у моделі присутній лише один стан «смерть», проте якщо метою моделі $є$ визначити причини смертності, таких станів може бути декілька.

Мета роботи: побудова ланцюга Маркова для прогнозування поширеності ішемічної хвороби серця (IXC) в Україні.

Результати та їх обговорення. Побудова ланцюга Маркова поширеності IXC в Україні. За визначенням Всесвітньої організації охорони здоров'я неінфекційні захворювання в XXI столітті стали однією з головних проблем для систем охорони здоров'я, негативно впливають на сталий розвиток і соціально-економічну структуру країн світу. Одночасно вони являються також найбільш поширеною причиною смерті. Перше місце в структурі загальної смертності стабільно посідають хвороби системи кровообігу, зокрема IXC [2].

Для побудови ланцюга Маркова поширеності IXC в Україні скористаємося епідеміологічними даними. Відповідно до аналізу захворюваності на IXC в Україні, наведеному у [1], у 2010 році поширеність IXC загалом по Україні становила 23 455,8 осіб на 100000 населення, захворюваність на IXC - 1708,4 на 100000 населення, первинна інвалідність - 3,8 на 10000 населення, смертність від IXC - 687,3 на 100000 населення. Загальна смертність по Україні в тому ж році відповідно до бази даних населення України [3] становила 1520 на 100000 осіб. Для повноцінного лікування IXC застосовують аорто-коронарне шунтування, що було проведено у 3,8 \% хворих [4].

Розглянемо можливі стани марковського ланцюга:

- $H$ - здоровий;

- $S$ - хворий на IXC;

- $B$ - хворий на IXC після аорто-коронарного шунтування;

- $I$ - хворий на IXC з інвалідністю;

- $D$ - мертвий.

Зауважимо, що під здоровою особою будемо вважати відносно здорових осіб, які не хворіють на IXC.

Розглянемо ймовірності переходів між можливими станами.

Здорова особа (стан $H$ ) може лишитися здоровою, захворіти на IXC або померти. Оскільки захворюваність становить 1708,4 на 100000 осіб, ймовірність переходу за один крок зі стану Н у стан $S$ становить:

$$
P_{H S}(1)=0,01708 \text {. }
$$

Оскільки загальна смертність становить 1520 на 100000 осіб, то ймовірність переходу за один крок зі стану $H$ у стан $D$ становить:

$P_{H D}(1)=0,0152$.

Тоді ймовірність здорової людини лишитися здоровою становить:

$$
P_{H H}(1)=1-0,01708-0,0152=0,96772 .
$$

Хворий на IXC (стан $S$ ) може лишитися хворим, отримати інвалідність, бути прооперованим і перейти у стан після аорто-коронарного шунтування або може померти. Оскільки первинна інвалідність при IXC становить 3,8 на 10000 населення, ймовірність за один крок перейти зі стану $S$ у стан $I$ становить:

$$
P_{S I}(1)=0,00038 \text {. }
$$

3,8 \% хворих проводять аорто-коронарне шунтування, тому ймовірність переходу зі стану $S$ у стан В становить:

$$
P_{S B}(1)=0,038 \text {. }
$$


Оскільки смертність хворих на IXC становить 687,3 на 100000 населення, а поширеність IXC загалом по Україні становила 23 455,8 осіб на 100000 населення, то ймовірність хворого померти від IXC становить 0,02930. Крім того, хворий може померти від іншої причини, а загальна смертність становить 1520 на 100000 осіб, тому ймовірність за один крок перейти зі стану $S$ у стан $D$ дорівнює:

$$
P_{S D}(1)=0,04450 \text {. }
$$

Тоді ймовірність хворого на IXС лишитися в стані $S$ дорівнює:

$$
P_{\text {Ss }}(1)=0,91712 \text {. }
$$

Хворий на IХС після аорто-коронарного шунтування (стан $B$ ) може лишитися у тому ж стані, повернутися до стану $S$ або померти. Однак проведене аорто-коронарне шунтування не виключає можливості розвитку атеросклеротичного ураження в інших ділянках коронарних судин, а від так, повторного розвитку нападів стенокардії або розвитку інфаркту міокарда. Тому ймовірність повернутися до стану $S$, як і зі стану $H$, дорівнює:

$$
P_{B S}(1)=0,01708 \text {. }
$$

Так само, як із стану $H$, ймовірність померти дорівнює:

$$
P_{B D}(1)=0,0152 .
$$

Тоді ймовірність лишитися в стані $B$ дорівнює:

$$
P_{B B}(1)=0,96672 \text {. }
$$

Хворий на IXC з інвалідністю (стан $I$ ) може лишитися у цьому ж стані, перейти у стан після аортокоронарного шунтування або померти. Аналогічно стану $S$, ймовірність померти дорівнює:

$$
P_{I D}(1)=0,0445 \text {, }
$$

а ймовірність того, що пацієнту зроблять аортокоронарне шунтування, дорівнює:

$$
P_{I B}(1)=0,038 \text {. }
$$

Тоді ймовірність лишитися у стані $I$ дорівнює:

$P_{I I}(1)=0,9175$.

Стан $D$ (мертвий) $є$ поглинаючим, 3 нього неможливо вийти, тому:

$P_{D D}(1)=1$.

Відповідно до наведених вище міркувань запишемо матрицю перехідних ймовірностей.

$$
P(1)=\left[\begin{array}{ccccc}
0,96772 & 0,01708 & 0 & 0 & 0,0152 \\
0 & 0,91712 & 0,038 & 0,00038 & 0,0445 \\
0 & 0,01784 & 0,96672 & 0 & 0,0152 \\
0 & 0 & 0,038 & 0,9175 & 0,0445 \\
0 & 0 & 0 & 0 & 1
\end{array}\right]
$$

Тоді ланцюг Маркова для хворих на IXC матиме вигляд, представлений на рис. 1.

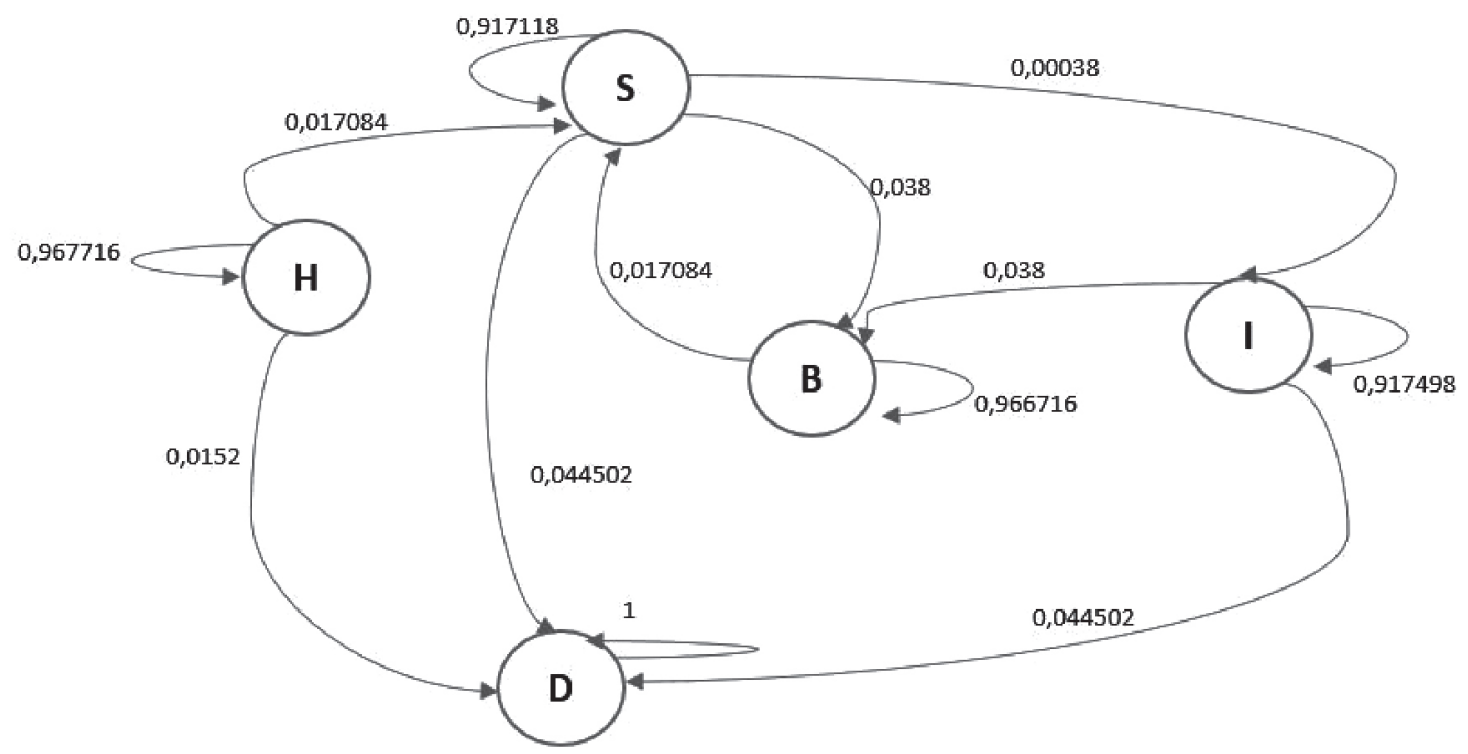

Рис. 1. Ланцюг Маркова для хворих на IXC 


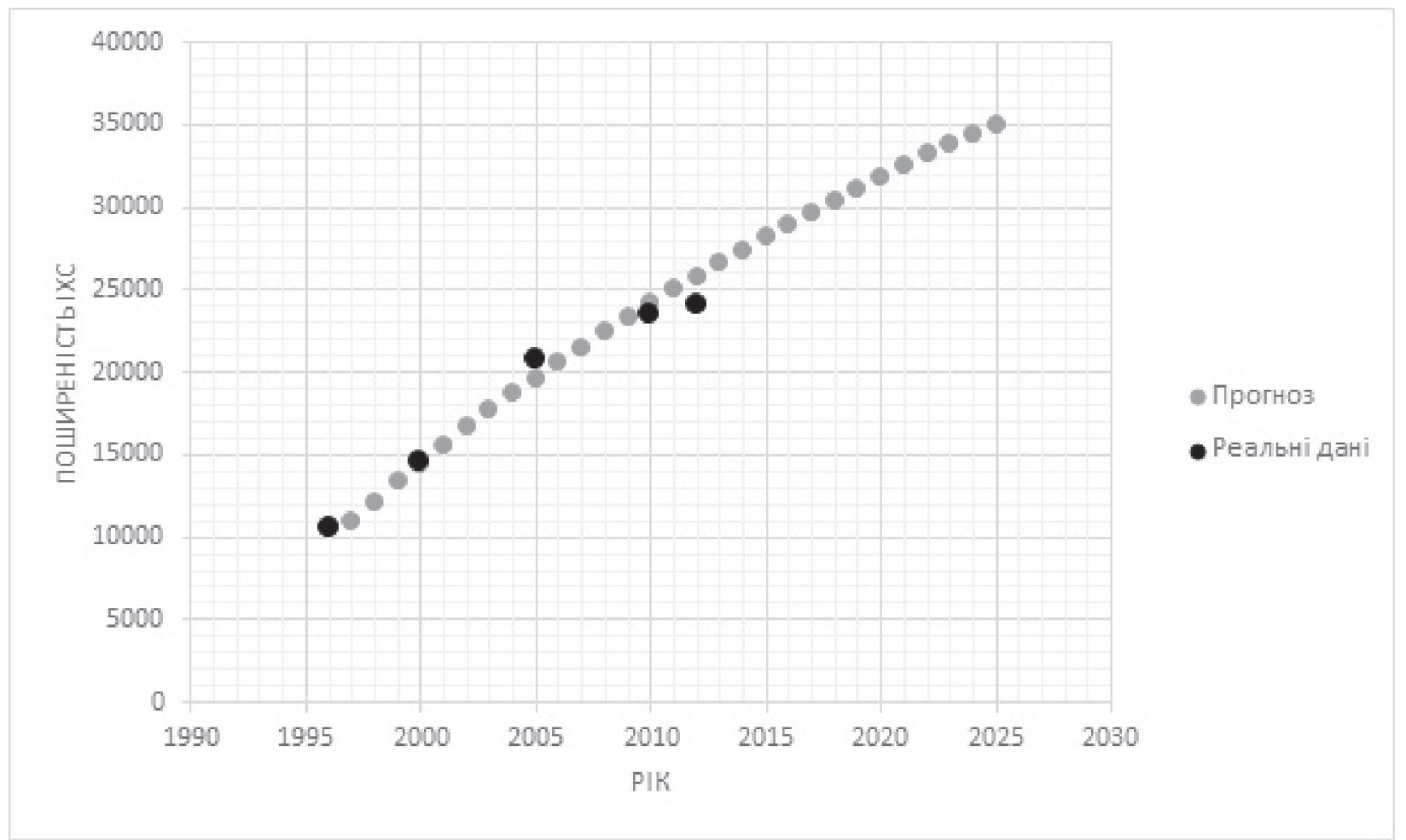

Рис. 2. Прогноз поширеності IXC в Україні

Розглянемо детальніше отриманий ланцюг Маркова. Первинним станом будемо вважати стан $H$. Стан $H \in$ нерекурентним, оскільки в цей стан можна прийти лише зі стану $H$. Стани $S$ та $B \in$ пов'язаними, оскільки зі стану $S$ можна досягнути стан $B$, а зі стану $B$ можна досягнути стан $S$. Стани $S$ та $I$ також $€$ пов'язаними, оскільки зі стану $S$ можна прийти в стан $I$, а зі стану $I$ можна прийти в стан $B$, з якого можна прийти в стан $S$. Стани $H, S, B, I \in$ неістотними, оскільки 3 кожного стану можна прийти в стан $D$, повернутися з якого неможливо. Стан $D \in$ істотним та ненульовим.

Прогнозування поширеності IXC. Для прогнозування поширеності IXC скористаємося методом Монте-Карло для марковських ланцюгів (MCMC). Для перевірки якості прогнозування побудуємо модель, починаючи з 1996 року, та порівняємо отримані за моделлю дані для 1996-2012 років з відомими епідеміологічними даними.

Населення України у 1996 р. становило 51060 000 осіб. Поширеність IXC у 1996 р. була 10 594,2 на 100 тис. населення, тобто хворих на IXС було 5409399 осіб. Розглянемо два можливі початкові стани $H$ та $S$ з ймовірностями $\mathrm{p}_{\mathrm{H}}=0.894058$ та $\mathrm{p}_{\mathrm{s}}=0.105942$. На рис. 2 наведено порівняння поширеності IXC, прогнозованої за МСМС, та реальної поширеності IXC, що була наведена у [5]. Середня похибка прогнозу становить 3,2 \%.

Прогнозуємо зростання поширеності IXC до 35 041,2 на 100 тис. населення у 2025 році. Зауважимо, що у 2016 році в роботі [5] було наведено аналогічний прогноз зростання поширеності IXC в Україні на 63,6 \% у 2025 році відносно 2014 року.

Висновки. Використання методу МонтеКарло для марковських ланцюгів у медичному прогнозуванні дає можливість прогнозувати поширеність неінфекційних захворювань у майбутньому і завдяки цьому проводити адекватну профілактичну роботу та планування щодо надання спеціалізованої медичної допомоги для відповідної нозології.

Поширеність IXC в Україні прогнозовано збільшиться до 35 041,2 на 100 тис. населення у 2025 році. 


\section{Література.}

1. Гандзюк В. А. Аналіз захворюваності на ішемічну хворобу серця в Україні / В. А. Гандзюк // Український кардіологічний журнал. - 2014. — № 3. - C. 45-52.

2. Коваленко В. М. Серцево-судинні хвороби: медичносоціальне значення та стратегія розвитку кардіології в Україні / В. М. Коваленко, А. П. Дорогой // Український кардіологічний журнал. - 2016. - Додаток 3. - С. 5-14.

3. Коефіцієнти смертності за статтю та віковими групами [Електронний ресурс] // База даних населення України. — Режим доступу : http://database.ukrcensus.gov. ua/Mult/Database/Population/databasetree_no_uk.asp

4. Соколов М. Ю. Реестр перкутанных вмешательств [Электронный ресурс] / М. Ю. Соколов // Режим доступа : http://wb.moz.gov.ua/download/seminarmfile/ c85cc4db70ecd42/.

5. Теренда Н. О. Основні тенденції та прогнозні оцінки загальної та первинної захворюваності на ішемічну хворобу серця в Україні / Н. О. Теренда // Вісник соціальної гігієни та організації охорони здоров'я України. - 2016. - Т. 69, № 3. - С. 31-35.

6. Beck J. R. The Markov process in medical prognosis / J. R. Beck, S. G. Pauker // Med. Decis. Making. — 1983. — Vol. 3, No. 4. - P. 419-434.

7. Sonnenberg F. A. Markov models in medical decision making: a practical guide / F. A. Sonnenberg, J. R. Beck // Med. Decis. Making. — 1993. Vol. 13. — P. 322-338.

\section{References.}

1. Gandzyuk, V. A. (2014). Analiz zakhvoryuvanosti na ishemichnu khvorobu sertsya v Ukraini [Analysis of the incidence of coronary heart disease in Ukraine]. Ukrains'kii kardiologichnii zhurnal (Ukrainian cardiology journal), 3, 45-52.

2. Kovalenko, V. M., \& Dorogoi, V. M. (2016). Sertsevosudinni khvorobi: medichno-sotsial'ne znachennya ta strategiya rozvitku kardiologii v Ukraini [Cardiovascular diseases: medical and social importance and strategy of cardiology development in Ukraine]. Ukrains'kii kardiologichnii zhurnal (Ukrainian cardiology journal), 3, 5-14.

3. Baza danikh naselennya Ukraini (database of the population of Ukraine). (n. d.). Koefitsienti smertnosti za stattyu ta vikovimi grupami [Mortality rates by sex and age group]. Retrieved from: http://database.ukrcensus. gov.ua/Mult/Database/Population/databasetree_no_ uk.asp.

4. Sokolov, M. Yu. (2016). Reestr perkutal'nykh vmeshatel'stv [Registry of percutaneous interventions]. Retrieved from: http://wb.moz.gov.ua/download/ seminarmfile/c85cc4db70ecd42/

5. Terenda, N. O. (2016). Osnovni tendentsii ta prognozni otsinki zagal'noi ta pervinnoi zakhvoryuvanosti na ishemichnu khvorobu sertsya $\mathrm{v}$ Ukraini [The main trends and predictive estimates of the total and primary incidence of coronary heart disease in Ukraine]. Visnik sotsial'noi gigieni ta organizatsii okhoroni zdorov'ya Ukraini (Bulletin of social hygiene and organization of public health services of Ukraine), 69(3), 31-35.

6. Beck, J. R., \& Pauker, S. G. (1983). The Markov process in medical prognosis. Med. Decis. Making, 3(4), 419-434.

7. Sonnenberg, F. A., \& Beck, J. R. (1993). Markov models in medical decision making: a practical guide. Med. Decis. Making, 13, 322-338. 